\title{
ON THE SOLAR RADIATION BUDGET AND THE CLOUD ABSORPTION ANOMALY DEBATE
}

\author{
ZHANQING LI \\ Department of Meteorology and ESSIC \\ University of Maryland, College Park, MD 20742, USA \\ E-mail: zli@atmos.umd.edu,http://www.atmos.umd.edu/ zli/
}

(Manuscript received 29 January 2003)

\begin{abstract}
This paper reviews the current state of knowledge, advances and challenges in short-wave earth radiation budget (ERB) studies and the cloud absorption anomaly (CAA) debate. The ERB issues deal exclusively with the solar energy disposition between the atmosphere, clouds and the surface. The ERB and its disposition have been derived from surface observations, satellite remote sensing and general circulation modeling. Major sources of uncertainties and discrepancies between observations and modeling are highlighted. Reported discrepancies between the ERB data sets obtained by various means are discussed, especially within the context of the recent debate concerning the CAA. This debate is documented thoroughly and critically in four stages: before and after the mid-1990s, and following two dedicated field experiments: the Atmospheric Radiation Measurement Enhanced Shortwave Experiment (ARESE I and II). An attempt is made to shed light on the causes of some controversial findings. It is now clear that the CAA is largely an artifact which does not emerge from a carefully designed closure test using the state-of-the-art radiative transfer models.
\end{abstract}

\section{Introduction}

Solar radiation is the ultimate source of energy for the planet Earth. Variable radiative heating/cooling in the atmospheric column drives vertical atmospheric convection, and global general atmospheric and oceanic circulations are the primary responses to the uneven distribution of the radiation budget. Modeling Earth's weather and climate and changes incurred by any external or internal forcing thus requires a good knowledge and understanding of the disposition and distribution of solar radiation, which is unfortunately still fraught with large uncertainties (Wild et al. 1995; Li et al. 1997; Arking 1999). Radiative transfer models founded on classical electromagnetic and quantum mechanics theories can compute the breakdown of solar energy in the atmosphere and at the surface. While the fundamentals of radiative transfer theories were well established about a century ago, it is still a daunting task to apply these theories to the complex real world in order to accurately compute the ERB. Complications stem from intricate and fickle cloud morphologies (commonly known as 3-D effects), odd ice crystal shapes, and multi-layer cloud structures, among other factors. Radiation processes are governed by a large number of radiatively sensitive variables that act on a wide range of scales (Wielicki et al. 1995). 
Solar energy reaching our planet is partly reflected to space, partly absorbed in the atmosphere, and partly absorbed at the Earth's surface. This partitioning of the solar energy incident at the top of the atmosphere (TOA), hereafter called the solar energy disposition (SED), is determined by the optical properties of the atmospheric column that, in turn, is influenced by the SED. The key variables that control the SED include the amount, vertical distribution, and optical properties of clouds, aerosol and radiation sensitive gases, as well as surface properties. Feedbacks involving these variables and the SED are important in modeling the climate system and its response to external perturbations, such as changes in the concentrations of $\mathrm{CO}_{2}$ and other greenhouse gases. At this point, cloud feedback is the principal contributor to the large uncertainty in the climate system response (Cess et al. 1989, 1996; Arking 1991). Not only does the SED play an active role in the energetics of the climate system, it is also closely linked to the hydrological cycle via dynamic and thermodynamic processes (Stephens and Greenwald 1991). About half the solar energy absorbed at the surface is used to evaporate water, which eventually forms clouds. Latent heat released during cloud formation is a major source of energy driving the atmospheric circulation, especially in the tropics, and is comparable in magnitude to the solar radiation directly absorbed by the atmosphere. A sensitivity study with a general circulation model (GCM) showed that modifying the partitioning of solar energy between the atmosphere and surface could substantially alter the modeled fields of cloud cover, temperature, precipitation, humidity, and the atmospheric circulation pattern (Kiehl et al. 1995). Understanding the Earth's climate and modeling it, therefore, requires an accurate representation of the radiation energy budget at the TOA (Hartmann et al. 1986; Ramanathan 1987) and at the surface (Suttles and Ohring 1986; Wielicki et al. 1996). Together they determine how much of the solar energy is absorbed in the atmosphere.

The importance of the earth radiation budget (ERB) has been underscored in numerous international programs. The Global Energy Water Cycle Experiment (GEWEX) has 5 projects directly related to the ERB including the Surface Radiation Budget SRB), the International Satellite Cloud Climatology Project (ISCCP), the Global Water Vapor Project (GVaP), the Global Aerosol Climatology Project (GACP), and the Baseline Surface Radiation Network (BSRN). Under the auspices of these projects, various ERB-related issues have been tackled. Among the largest undertakings that have flourished during the past decade are the Earth Observation System (EOS) of the National Aeronautics and Space Administration (NASA) and the Atmospheric Radiation Measurement (ARM) program of the Department of Energy (DOE) (Ackerman and Stokes 2003)

In light of the importance and quick development of these major earth science enterprises, this paper reviews some major advances made in the past few decades and challenges that still confront us. The review is focused on two intimately related and yet fastdeveloping topics, namely the solar radiation budget and its disposition, and the cloud absorption anomaly. 


\section{The Solar Radiation Budget}

The ERB in the atmosphere-surface system has been monitored from space for more than two decades, while the surface radiation budget (SRB) has been observed at various sites, unevenly distributed over the globe, for more than a century. Both ERB and SRB observations have limitations on their accuracy, making it difficult to obtain a reliable estimate of the energy absorbed in the atmosphere since the latter is often determined as the difference between two large quantities. Consequently, fervent debate has been waged over the past 10 years or so concerning the amount of solar energy absorbed inside the atmospheric column as discussed in the following section.

\subsection{Surface Observations}

Prior to the space-borne Earth observation era inaugurated in the $1960 \mathrm{~s}$, radiation estimates were based primarily on surface measurements, although simple models of radiative transfer in the atmosphere were used to infer TOA fluxes from the surface measurements. Surface radiation is among the few meteorological variables that have been observed since the last century (Hunt et al. 1986). On the basis of very limited observations at different latitudes, Abbot and Fowle (1908) obtained the first estimate of the global annual mean planetary albedo (0.37) and near-surface (below $1800 \mathrm{~m}$ ) absorption (0.42). All numbers are normalized to the incoming solar flux at the TOA. Other investigators obtained similar estimates of the SED in the 1920s and 1930s (c.f. Table 3.2 of Budyko 1982). Spatial and temporal variations in the SED were first addressed by Simpson (1929). More extensive analyses were made in the middle of the 20th century (Houghton 1954; Budyko 1956; London 1957), based on increased surface observations, more sophisticated radiative transfer theory, and the beginnings of laboratory studies. Table 1 summarizes observation-based estimates of SED.

Table 1. Comparison of historical estimates of the solar energy disposition estimated from ground and/or satellite (*) observations (After Li et al. 1997).

\begin{tabular}{lllll}
\hline Sources & Coverage & TOA & Surface & Atmosphere \\
Abbot \& Fowle (1908) & NH & 0.37 & 0.42 & 0.21 \\
Houghton (1954) & NH & 0.34 & 0.47 & 0.19 \\
London (1957) & NH & 0.35 & 0.475 & 0.175 \\
Sasamori et al. (1972) & SH & 0.35 & 0.45 & 0.20 \\
Budyko (1982) & Global & 0.30 & 0.46 & 0.24 \\
Pinker \& Laszlo (1992) & Global & 0.29 & 0.50 & 0.21 \\
Ohmura \& Gilgen (1993) & Global & 0.30 & 0.42 & 0.28 \\
Li \& Lighton (1993)* & Global & 0.30 & 0.46 & 0.24 \\
Rossow \& Zhang (1995)* & Global & 0.32 & 0.48 & 0.19 \\
& & & & \\
\hline
\end{tabular}


Note that the most extensive and complete compilation of the global surface energy balance (SEB) was carried out by Budyko (1982) and his colleagues. They generated several versions of the SEB atlas depicting the monthly-mean global distribution of various SEB components, including the SRB. Empirical relationships involving conventionally measured meteorological variables (e.g., cloud amount, sunshine duration, etc) were adopted. With improving techniques and a growing set of observations, their estimates of solar flux absorbed at the surface increased (Budyko 1982). Their latest estimates of the SED are nearly identical with the satellite-based estimates of $\mathrm{Li}$ and Leighton (1993). Interestingly, a recent ground-based estimate of surface absorption by Ohmura and Gilgen (1993) is similar to an earlier estimate by Abbot and Fowle (1908). The fact that a discrepancy exists between the two contemporary estimates of surface absorption, encompassing a range as much as reported in history, is a good testimony to the complexity of the problem. The problem is also attributed to meager ground-truth information available to characterize the SRB. Given a long history of ground-based radiometric observations, we are still confronted with large uncertainties despite the improved quality of radiometers (Michalsky et al. 1999; Dutton et al. 2001) employed in dedicated radiation campaigns such as the ARM program. Moreover, surface SRB measurements suffer from an inability to maintain uniform deployment standards and proper calibration, in addition to the problem of inadequate spatial sampling. Most of all, the surface measurements do not provide any information on radiation budget at the TOA which is best quantified by satellite observations.

\subsection{Satellite Remote Sensing}

Since 1960, meteorological satellites have radically advanced our knowledge of the ERB (House et al. 1986). In contrast to ground-based observations, space-borne observations have the advantage of a global coverage. From the space-borne radiometers of the first (TIROStype) and second generations (Nimbus 3, ESSA and NOAA series), a global mean planetary albedo was found to be around 0.30 (Vonder Haar and Suomi 1971; Stephens et al. 1981). This estimate is significantly lower than the pre-satellite estimates but agrees fairly closely with the later observations by much more advanced sensors (c.f. Table 1) (Hartmann et al. 1986; Ramanathan 1987; Barkstrom et al. 1989). The geographical distribution of the TOA albedo for the four seasons was obtained by Raschke et al. (1973). These early estimates of regional radiative fluxes contain large uncertainties due in part to the crude treatment of the dependence of satellite radiance measurements on viewing geometry (Arking and Levine 1967; Raschke et al. 1973).

More meticulous monitoring of the spatial and temporal variations in the TOA albedo was accomplished by the third-generation radiometers, including the Earth Radiation Budget (ERB) sensors aboard Nimbus-7 (Jacobowitz et al. 1984) and the Earth Radiation Budget Experiment (ERBE) sensors aboard three satellites (Barkstrom et al. 1989). One of the major advances was the development of improved angular dependence models (ADMs) (Taylor and Stowe 1984; Suttles et al. 1988). Nevertheless, angular correction has been the primary source of uncertainty in ERB measurements (Arking and Vemury 1984; Stuhlmann and Raschke 1987; Suttles et al. 1992; Wielicki et al. 1995; Li 1996). The uncertainty results from 
difficulties in accounting for the dependence of the ADM on many variables such as surface and cloud properties. Chang et al. (2000) demonstrated a strong dependence of the ADM on cloud optical depth and cloud phase and derived a set of ADMs as a function of these variables using the French ScaRaB satellite data. The most extensive ADMs are being developed for the fourth generation of the ERB mission (Wielicki et al. 1996), which is expected to reduce the ADM-related uncertainty to less than 1\% (Loeb et al. 2002). While well-calibrated broadband radiation measurements are most desirable, such data are only available from non-continuous experimental missions such as the Nimbus series, ERBE and CERES. Between these missions, there exist significant gaps, e.g. 8 years between ERBE and CERES. To fill such gaps, non-calibrated narrowband imager data were often utilized to estimate broadband fluxes, thanks to the strong correlation between the two quantities (Minnis and Harrison 1984; Li and Leighton 1992; Li and Trishchenko 1999). Lack of onboard radiometric calibration is a major source of error in these estimates (Trishchenko and Li 1998), which can be overcome/reduced by comparing the estimates against those from calibrated imaging sensors that were launched in recent years, e.g. the Visible Infrared Scanner (VIRS) and Moderate Resolution Imaging Spectroradiometer (MODIS) (Minnis et al. 2002).

Since a scanning radiometer only measure radiances exiting from the entire atmospheresurface system, surface and atmospheric radiation budgets cannot be directly determined from satellites. Considerable success has been achieved in the retrieval of the solar SRB from TOA reflected flux or albedo measurements, as reviewed by Schmetz (1989) and Pinker et al. (1995). The retrieving algorithms generally fall under three categories: empirical relationships (Fritz et al. 1964; Tarpley 1979; etc.), parameterized schemes (Gautier et al. 1980; Chou 1989; Li et al. 1993) and radiative transfer models (Möser and Raschke 1983; Pinker and Ewing 1985; Stuhlmann et al. 1990; Rossow and Zhang 1995; etc). The first satellite-based estimation of the SED was made by Hanson et al. (1967) over the United States for the spring of 1962. Global SED data sets of multiple years are now available from both operational meteorological satellites (Pinker and Laszlo 1992; Rossow and Zhang 1995) and radiation research satellites ( $\mathrm{Li}$ and Leighton 1993). The global mean surface absorptance estimated from these satellite observations ranges from 0.46 to 0.50 (Table 1). For a planetary albedo of 0.30, the global mean atmospheric absorptance therefore varies from 0.20 to 0.24 . To understand why such a discrepancy in atmospheric absorptance exists, Li (1995) examined the differences between two global SRB datasets derived from ISCCP using the algorithm of Pinker and Laszlo (1992) and from ERBE using the algorithm of Li et al. (1993). It was found that use of different input datasets leads to random discrepancies, while systematic discrepancies (global mean being 0.2 versus 0.24 ) were traced to the use of an outdated water vapor absorption scheme (Lacis and Hansen 1974) in Pinker and Laszlo (1992). Replacement of this old scheme with a new water vapor absorption scheme essentially removed the systematic difference. This finding is corroborated with an independent validation study ( $\mathrm{Li}$ et al. 1995) that shows no systematic difference relative to global ground-based radiation measurement. Figure 1 presents a sound estimate of the SED according to ERBE satellite measurements of the ERB and satellite-based retrievals of the 
SRB (Li and Leighton 1993) (Wielicki et al. 1995). It should be pointed out, however, that the SRB is likely subject to large errors for regional and instantaneous values due in part to a lack of corrections for some secondary factors that could become dominant, such as aerosols, in heavy biomass burning regions ( $\mathrm{Li}$ 1998; $\mathrm{Li}$ and Kou 1998). Modifications have been made to improve the SRB retrievals by accounting more explicitly for the effects of aerosol, ozone, cloud droplet size (Masuda et al. 1995) and ice cloud variables (Zhang et al. 2002).

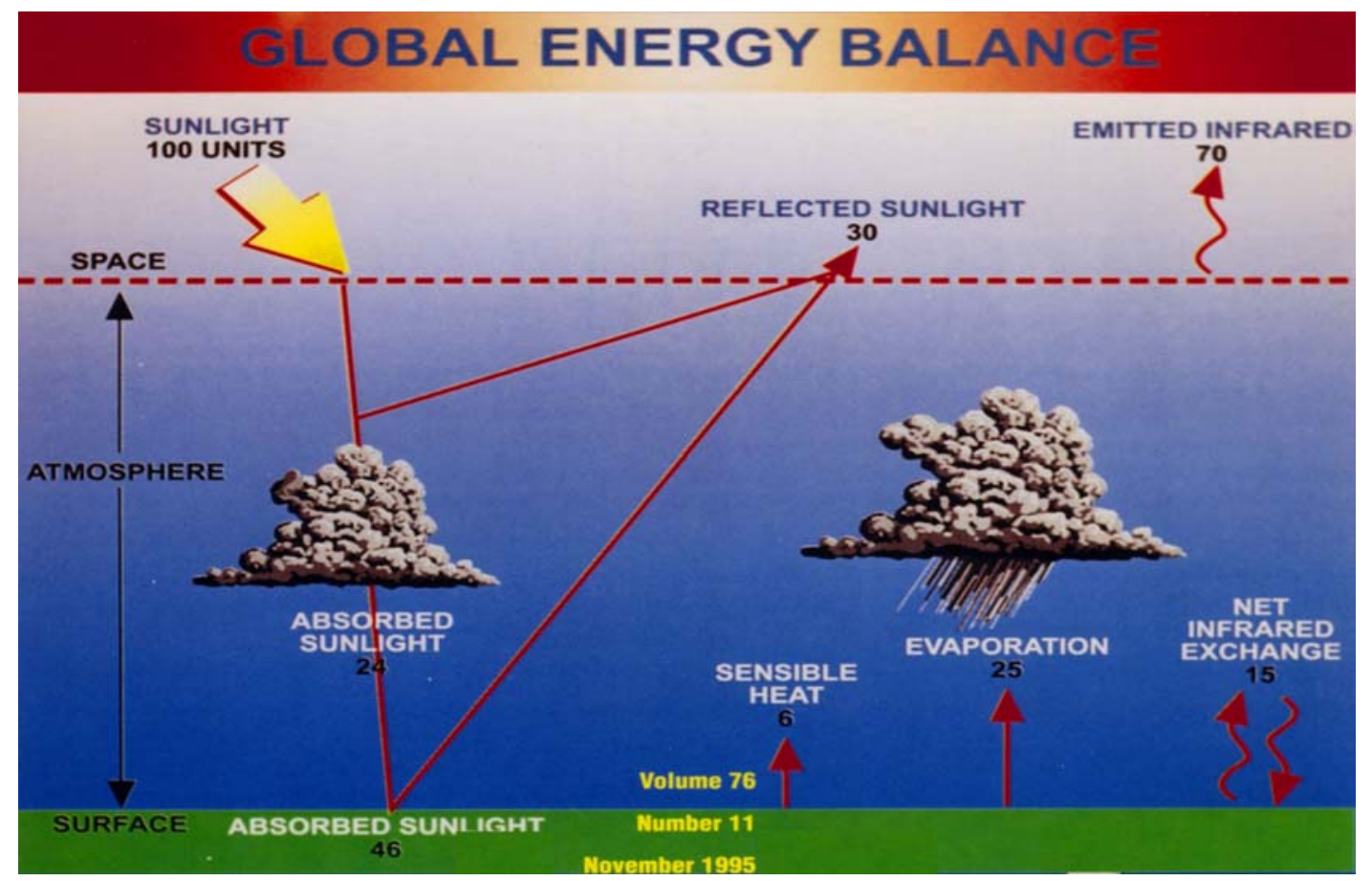

Figure1. The revised global energy balance per ERBE satellite observations of the radiation budget at the TOA and inference of the surface solar radiation budget by Li and Leighton (1993) (the cover of the Bulletin of American Meteorological Society from an article by Wielicki et al. (1995)).

\subsection{GCM Modeling}

In general circulation models (GCMs), the solar energy disposition is computed by fast radiative transfer codes with input parameters provided by the GCM. Since GCMs generally do not reproduce cloud properties well, barring more sound cloud amount and distribution, and since clouds are the most important factor in determining the SED, the SED from a GCM usually incurs larger uncertainties. However, the majority of GCMs may have been tuned to produce "reasonable" values for such highly averaged quantities as global and annual mean SED. In any event, a comparison of the SED from a model and from observations can help evaluate and improve the performance of the GCM. To evaluate the performance of a GCM, we need not only reliable observations of the SED, but also dependable estimates of the variables that influence the SED. The SED is mainly modified by clouds (fractional cover, 
thickness, height, microphysical parameters), water vapor (amount and vertical distribution), aerosols (amount, vertical profile, size distribution and optical properties), and surface albedo (including its spectral and angular dependencies). To date, many of these variables can be derived from satellite observations such as cloud from ISCCP (Rossow and Schiffer 1991) and surface albedo from ERBE ( $\mathrm{Li}$ and Garand 1994). With these values, one is able to interpret the difference between modeled and observed SED in terms of the treatment of various physical processes and radiative transfer algorithms (Barker et al. 1994; Barker and Li 1995; Kiehl et al. 1994; Wild et al. 1995; Ward 1995; among others).

\subsection{Comparison of Observations, Inversions and Modeling}

Li et al. (1997) compared eight global radiation data sets: one based on surface observations that are extended globally using empirical relationships, three based on estimates from satellite measurements, and four from GCM simulations. Comparisons were made for global and annual means and zonal and monthly means, under both clear and all-sky conditions. Overall, the agreement at the top of the atmosphere is much better than at the surface and in the atmosphere. Global and annual mean TOA albedos generally agree to within 0.02 , whereas atmospheric absorptances differ by over 0.1 . In terms of the global and annual mean flux absorbed at the surface, the maximum difference is nearly $50 \mathrm{Wm}^{-2}$. More importantly, surface fluxes computed by models are usually larger than ground-based observations and satellite-based estimates. Satellite- and ground-based values agree well under most circumstances, except for regions affected by strongly absorbing aerosols. Since such an effect is limited to a portion of the continental areas, it does not alter significantly zonal and global mean solar radiation budgets.

The discrepancies between satellite-based estimations and model simulations are on the order of $20 \mathrm{Wm}^{-2}$ to $25 \mathrm{Wm}^{-2}$, comparable to those found from direct comparisons between model simulations and surface observations. Therefore, two critical issues need to be addressed. First, it is necessary to narrow the large gap in our knowledge of the partitioning of the solar energy between the atmosphere and surface. This requires better and more consistent observations. Second, it is necessary to determine why there is a discrepancy between models and observations, if a discrepancy remains after the observations are better established. As the differences of similar magnitude also exist under clear-sky conditions (Li et al. 1997; Randall et al. 1992), it was argued that the model deficiency stems mainly from clear-sky calculations. The analyses of zonal comparisons further suggest that the use of dated schemes for water vapor absorption (Li 1995) and neglect of absorbing aerosols are the two major factors causing the under (over)-estimation of atmospheric (surface) absorption (Francis et al. 1997). This finding was challenged by claims of a substantial cloud absorption anomaly reported in the mid-1990s that was the subject of a major controversy in the atmospheric radiation community. Note that the CAA was not a new discovery but it was the renewed debate that caught the attention of the climate community at large due to its immense implications for climate modeling. The following section is devoted to the debate. 


\section{The Cloud Absorption Anomaly (CAA) Debate}

\subsection{Historical Debate Prior to the 1990s}

The debate over the existence of a CAA has been ongoing for over half a century. An early discovery of a discrepancy between model calculated and observed cloud absorption was reported by Fritz (1951). Contradictory findings of disagreement (e.g. Robinson 1958; Reynolds et al. 1975; Foot 1988) and agreement (Slingo et al. 1982; Herman and Curry 1984; Hignett 1987; Rawlins 1989) between measured and calculated cloud absorption have since been reported from time to time. Stephens and Tsay (1990) reviewed all reported CAAs within the context of various proposed explanations. It was concluded that broadband absorption measurements were subject to such large uncertainties that some reported anomalies could not be established but an absorption anomaly in the near-infrared (NIR) appeared to be somewhat real. The large droplet theory proposed by Wiscombe et al. (1984) is too small to explain most reported CAA. Absorbing aerosols may contribute to the purported CAA, but would be limited primarily to the visible region where little evidence of a CAA has been reported. The effects of the continuum absorption by water vapor in the NIR and heterogeneous clouds may contribute to a CAA to some degree, but does not seem to be a leading or sole factor. Note that the majority of CAAs reported prior to the 1990s has a magnitude comparable to or smaller than uncertainties incurred in observation and modeling. As both observation techniques and modeling capability advance, some of the reported CAAs may no longer be valid. This is, however, unlikely the case for the renewed CAA debate since the mid-1990s, as reviewed below.

\subsection{Renewed Debate since the Mid-1990s}

The renewed debate was ignited by three studies claiming that the solar radiation absorbed by clouds is substantially underestimated by models (Cess et al. 1995; Ramanathan et al. 1995; Pilewskie and Valero 1995). Except for the study of Pilewskie and Valero (1995), which follows the traditional approach of using aircraft to directly measure cloud absorption, the other two studies deal with atmospheric column absorption using ground and TOA fluxes. Since the absorption bands of water vapor and water droplets are highly overlapping and are of similar magnitudes (Davies et al. 1984), total absorption in the atmospheric column is supposed to be rather insensitive to cloud, except for modification of its vertical distribution. Having a small effect on atmospheric absorption, however, does not imply that clouds absorb little solar radiation, only that whatever absorption occurs, the bulk of it is in place of clear-sky absorption (Stephens 1996). As a result, solar cloud radiative forcing (CRF) (the difference in net solar flux between cloudy and clear skies) at the surface is close to, or slightly larger than that at the TOA, according to our conventional wisdom of radiative transfer.

Using satellite and ground-based measurements made at a handful of tropical and midlatitude sites, the studies of Ramanathan et al. (1995) and Pilewskie and Valero (1995) found that the ratio of surface to TOA CRF is not only significantly larger $(\sim 1.5)$ than unity, but 
also invariant in terms of global distribution. The amount of underestimation in solar radiation absorbed by clouds was found to be on the order of $25 \mathrm{Wm}^{-2}$ (daily average), comparable to the average discrepancy between models and observations. If these findings were true, it would cause the biggest change in our understanding of the Earth's energy balance since the late 1960s, when emerging satellite observations helped revise the planetary albedo substantially (Wiscombe 1995). Chou et al. (1995) pointed out that to reach such a high ratio would require an increase in the single-scattering albedo of cloud droplets by a factor of 40 in the NIR, assuming no absorption in the visible region as supported by previous studies (Stephens and Tsay 1990) and also later by Li and Kou (1998). Since absorption in the NIR is proportional to cloud droplet size (King et al. 1990), the finding implies that either the fundamentals of radiative transfer theory originating from the Maxwell equations are seriously flawed, or cloud droplets must be huge; the latter would be at odds with the plethora of in-situ measurements.

Employing quality-controlled radiation data measured around the globe at the surface, together with calibrated ERBE satellite data, Li et al. (1995) reached a nearly opposite conclusion that the CRF ratio is essentially close to unity and varies with season and region (except for some tropical sites where the ratio reaches 1.5). Both the magnitude and variation were explained by extensive model simulation results ( $\mathrm{Li}$ and Moreau 1996). The high values in certain parts of the tropics were later found to stem from heavy smoke aerosols generated by biomass burning where the strong absorption led to an erroneous estimation of clear-sky fluxes. After correcting the errors, Li (1998) obtained CRF ratios near 1. Under the assumption that clouds were as strongly absorbing as reported, Ackerman and Toon (1996) were unable to simulate the persistent existence of stratocumulus cloud along the west coast of the United States, simply because the excessive absorption "burns out" cloud droplets once they are formed.

Meanwhile, the analysis methods used to support and challenge the CAA were brought under scrutiny (Stephens 1996; Arking et al. 1996; Imre et al. 1996; Barker and Li 1997; Cess et al. 1997; Zhang et al. 1998). Among others, a major concern regarding methodology lies in whether one should use instantaneous or spatially and temporally averaged TOA albedo and surface transmittance data for regression analysis between the two variables. Note that the slope of the regression may serve as a proxy of cloud absorption under the assumption that no exchange of photons occurs horizontally. Instantaneous radiative flux measurements made at individual sites were employed by Cess et al. (1995), whereas monthly mean fluxes averaged over a month and over grid areas of $280 \mathrm{~km}^{2}$ were used in Li et al. (1995) and Li and Moreau (1996).

To help unravel this issue, we derive here a simple conceptual relationship between the slope(s) and cloud absorption. By energy conservation,

$$
R_{t o a}+A_{a t m}+I_{s f c}\left(1-R_{s f c}\right)+T_{h o r}=I_{t o a}
$$

where $I_{\text {toa }}$ denotes the incoming solar radiation at the TOA which is distributed in four ways namely, reflection at the TOA, absorption in the atmosphere and at the surface, and horizontal transportation (positive if losing photons and negative if receiving photons). Radiative 
transfer modeling has shown that atmospheric absorption is a linear function of TOA albedo (Li et al. 1993):

$$
A_{\text {atm }}=a+b R_{\text {toa }} .
$$

Note that the coefficient $b$ is usually very small, since atmospheric column absorption depends weakly on clouds. While no specific relation between $T_{\text {hor }}$ and $R_{\text {toa }}$ was established, it is known that $T_{h o r}$ is also positively correlated with $R_{\text {toa }}$, in that a region of more cloud deflects (net effect) photons toward an adjacent clear or less cloudy region. To the first order of approximation, we may assume the relation is linear,

$$
T_{\text {hor }}=c+d R_{\text {toa }}
$$

Substituting Eqs. (2)-(3) into (1) and rearranging it, we can derive a linear relation between TOA reflected and surface transmitted fluxes:

$$
R_{t o a}=e-s I_{s f c}
$$

where the slope is given by:

$$
s=\left(1-R_{s f c}\right) /(1+b+d) .
$$

Note that in a plane-parallel model, the coefficient $d$ vanishes to zero, i.e. no horizontal energy exchange is allowed, which is the assumption used in GCMs. Using typical values for $R_{s f c}$ and $b, s$ turn out to be around 0.8, as was found by Cess et al. (1995). In nature, however, there rarely exists a uniform cloud that has no net horizontal exchange of photons. So long as photon exchange takes place, $d$ is a non-zero positive value leading to a slope that is bound to be smaller than that derived from plane-parallel simulations. This was confirmed by Monte Carlo simulations that can modulate the horizontal exchange of photon (Barker and Li 1997). For the same cloud, the slopes resulting from no photon exchange are always significantly larger than those that include the horizontal exchange of photons, despite the fact that the cloud possesses the same optical properties.

These arguments are illustrated more clearly in Fig. 2. The left panel demonstrates how reflection and transmission of solar energy are altered by the horizontal exchange of solar photons, while the right panel shows how the exchange affects the slope. For nonhomogeneous clouds, a thicker cloud (or a portion of the cloud that is relatively thick) loses solar energy due to scattering by the cloud edge. As a result, its reflection and transmission are both reduced relative to a plane-parallel cloud of the same cloud thickness and containing the same microphysics. On the contrary, over clear or less cloudy regions, both reflection and transmission are enhanced by the incoming photons scattered by the neighboring thicker clouds. Consequently, the slope of the regression between TOA reflection and surface 
transmittance is lowered relative to the slope determined by a plane-parallel one-dimensional model, as used in GCMs. This is illustrated in the right panel. It is thus an ill posed comparison between the slopes derived from observations of instantaneous fluxes and GCMmodeled fluxes. On the other hand, the comparison would be meaningful if observations were averaged over a spatial and/or temporal domain that is large enough to effectively remove the effect of photon horizontal exchange. Use of monthly-mean fluxes averaged over the GCM grids may be sufficient in this regard (Li et al. 1995).
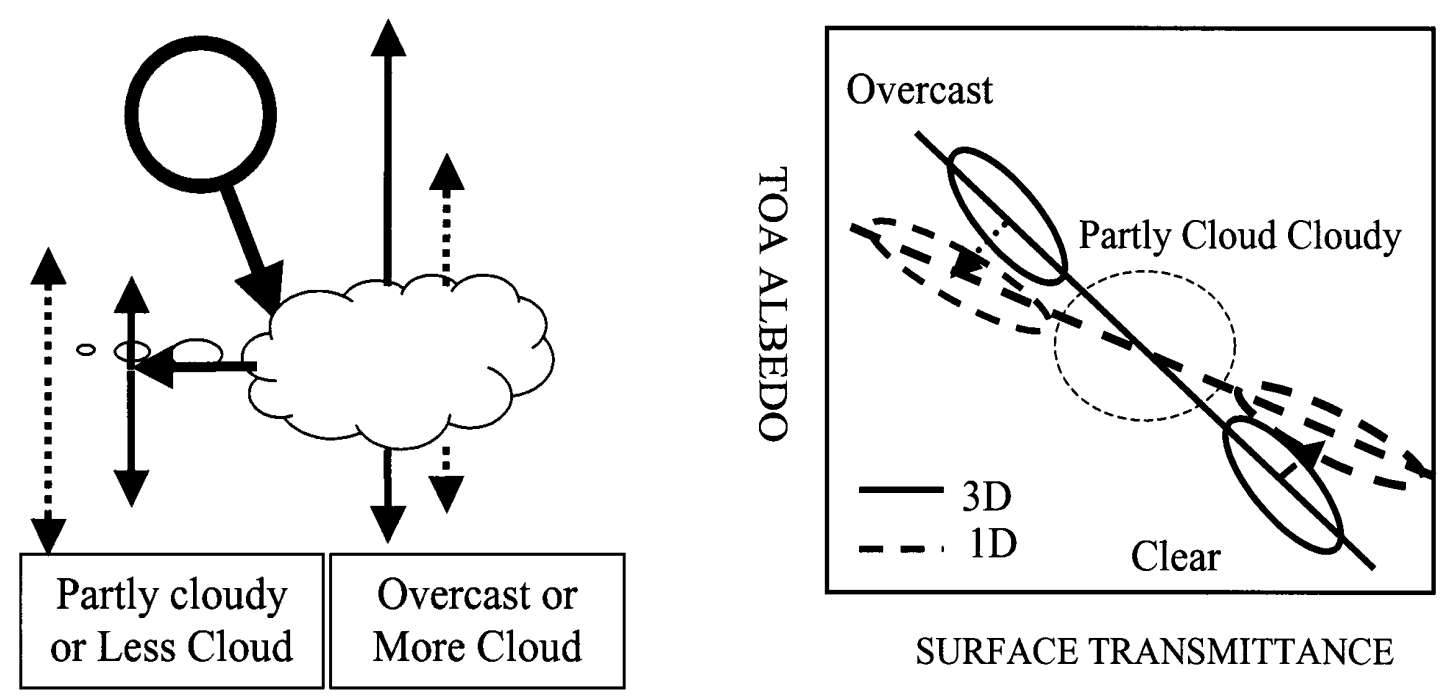

Figure 2. A schematic of the horizontal exchange of solar photons and its impact on the slope of the regression between TOA albedo and surface transmittance. The dashed and solid arrows in the left panel illustrates changes in the amounts of solar radiation reflected and transmitted with and without photon horizontal exchange. The right panel demonstrates resulting changes in albedo and transmittance.

Another closely related debate is concerned with analysis of measurements made by two aircraft flying in stack below and above a cloud (Marshak et al. 1997). Horizontal linkage of photons has also been blamed for apparent CAA in studies using aircraft data. This problem can be remedied by subtracting the apparent cloud absorption in the visible or any nonabsorbing band following the original or modified Ackerman and Cox (1981) approach (Marshak et al. 1999). This apparent effect should not be mixed with the real effect of 3-D cloud in altering cloud absorption. Throughout the course of the debate, controversial findings on the magnitude of absorption enhancement have also been reported, ranging from very significant (Byrne et al. 1996), significant (at steep solar zenith angles only) (O'Hirok et al. 1998) to negligible (Markshak et al. 1998, Barker et al. 1998).

Another factor that may lead to the apparent CAA is the influence of aerosols. Li and Trishchenko (2001) demonstrated that absorbing aerosols usually exert much less influence on the TOA radiation budget than the surface radiation budget. The ensuing larger surface aerosol radiative forcing could be attributed to a surface cloud radiative forcing resulting 
from excessive cloud screening, leading to overestimation of the surface to TOA cloud radiative forcing ratio and thus the apparent CAA.

\subsection{Inconclusive Findings from the ARESE I}

To help resolve the CAA debate, the U.S. Department of Energy sponsored a field experiment in the fall of 1995 dubbed the ARM Enhanced Shortwave Experiment (ARESE), conducted around the ARM Southern Great Plains (SGP) Central Facility (CF) site in northcentral Oklahoma. Following the ARESE, an even larger unexplained CAA was reported (Valero et al. 1997; Zender et al. 1997). Valero et al. (1997) employed collocated measurements of upwelling and downwelling radiative fluxes measured by their Total Solar Broadband Radiometer (TSBR) on two stacked aircraft (above and below cloud). They reported that cloud absorption increases dramatically with cloud amount and the largest discrepancy between model and observation occurred on a heavy overcast day (October 30), 1995. They reported that the cloud layer between the aircrafts absorbed $37 \%$ of the incoming solar irradiance. In comparison, model estimation of total atmospheric absorptance is usually less than 24\% ( $\mathrm{Li}$ et al. 1997). In a companion study, Zender et al. (1997) reported a mean discrepancy of about $100 \mathrm{Wm}^{-2}$ in cloud absorption on the same day. Although Zender et al.'s study employed ground-based surface measurements, their CAA originated from the same measurements, namely, Valero et al.'s airborne measurements of the upwelling flux. The quality of these measurements was called into question by Li et al. (1999). They found that cloud albedo measurements from the Valero's broadband instrument are systematically and substantially smaller than those estimated from the Scanning Spectral Polarimeter (SSP) (Stephens et al. 2000), a well-calibrated airborne radiometer with an accuracy of $\pm 3-5 \%$.

An extensive consistency analysis was carried out by Li et al. (1999) using a variety of data sets acquired from various platforms including ground-based cloud radar data, microwave water vapor data, surface spectral and broadband radiation data, satellite data, airborne spectrometers and broadband radiometers. The spectral albedos were consistent with all other measurements, while Valero's broadband reflected flux data differed considerably from others. Valero et al. (2000) later admitted that their cloud albedo on this heavy overcast day was underestimated but not to the degree found by Li et al. (1999). They maintained that their aircraft data was generally sound and argued that their revised data agreed well with simultaneous GOES-8 satellite measurements. Note that the GOES-based broadband albedo values were estimated from GOES visible reflectances, following vicarious calibration and narrow-to-broadband conversion by Minnis and Smith (1998). Recently, Minnis et al. (2002) found that the calibration gain used in Minnis and Smith (1998) is underestimated by $9 \%$ relative to measurements from on-board calibrated sensors of the VIRS and MODIS. This finding reinforces the argument of $\mathrm{Li}$ et al. (1999) that the large CAA resulting from the ARESE by Valero et al. (1997) and Zender et al. (1997) is an artifact originating from erroneous observations. The error in the calibration gain also explains why the discrepancy decreases with cloud amount as noted by $\mathrm{Li}$ et al. (1999). It is also plausible that the calibration error could have contributed to the CAA finding by Cess et al. (1995) who employed similar GOES-based TOA albedos. 


\subsection{Conclusive Findings from ARESE II}

The controversial findings from the first ARESE motivated the second experiment conducted in the spring of 2000. To solve the calibration conundrum resulting from ARESE I, ARESE II devoted much effort into instrument calibration and intercomparison (Michalsky et al. 2001). Several sets of spectral and broadband radiometers were deployed and intercompared and in general, all agreed to within $10 \mathrm{Wm}^{-2}$. Independent investigations ( $\mathrm{Li}$ et. al. 2002; Ackerman and Stokes 2003) did not find a cloud absorption anomaly anywhere close to that claimed before, although a small discrepancy on the order of $20 \mathrm{Wm}^{-2}$ (instantaneous value) exists. While one cannot negate a CAA of smaller magnitude, if exists, it must be viewed within the framework of various uncertainties due to measurement uncertainties $\left(\sim 10 \mathrm{Wm}^{-2}\right)$, mismatch between ground and aircraft observations $\left(<20 \mathrm{Wm}^{-2}\right)$, model calculations $(<20$ $\mathrm{Wm}^{-2}$ ), and errors in input data of unknown magnitude.
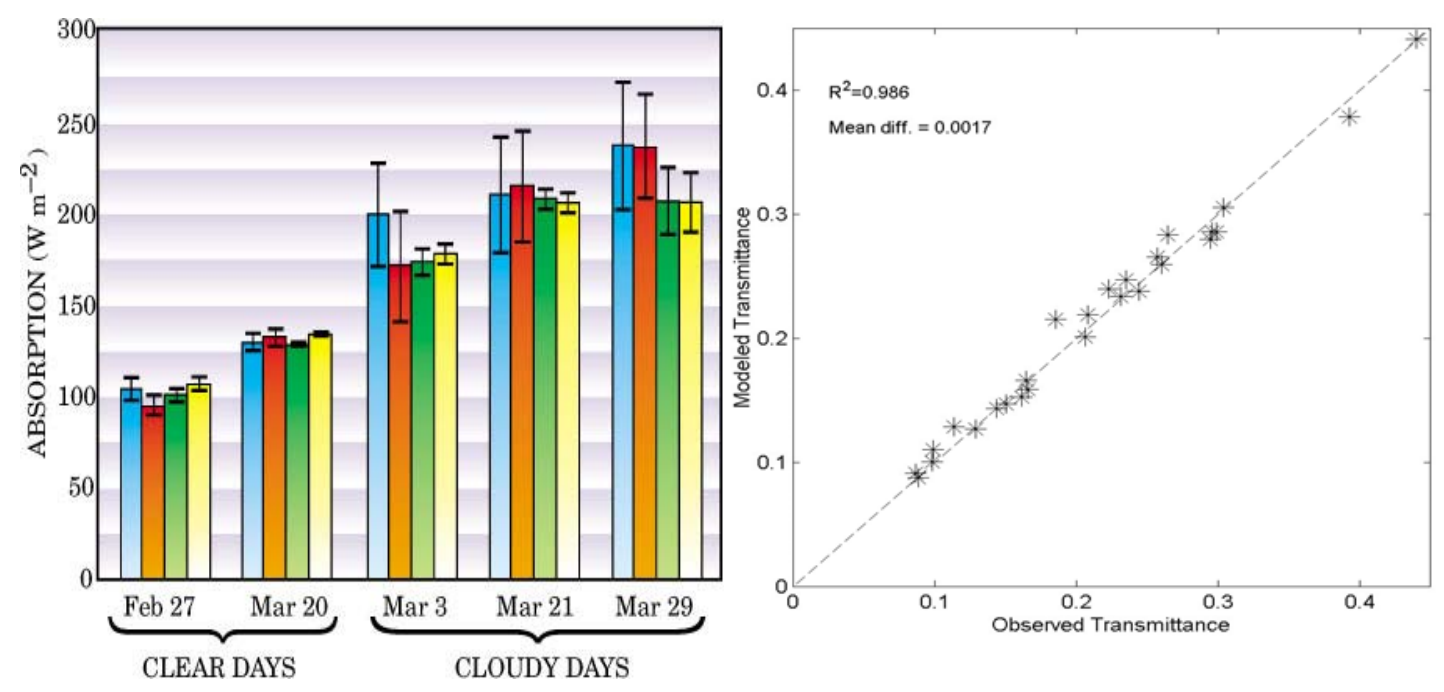

Figure 3 The left panel shows comparisons of atmospheric column absorption from the ground up to $7 \mathrm{~km}$ measured by ground and aircraft observations (blue and red) and computed by models (green and yellow) on two clear days and three cloudy days in 2002 (after Ackerman and Stokes, 2003. The right panel shows a comparison between observed and modeled broadband atmospheric transmittance using areal-mean surface albedo (after Li et al. 2002).

Li et al. (2002) found much of the discrepancy in the NIR may be caused by surface heterogeneity surrounding the ARM CF. The ARESE II was conducted over the ARM CF (dry grass and bare soil) where the surface albedo is systematically smaller than that over the surrounding area which was primarily covered by winter wheat. Over the large field of view seen by the downward radiometer, atmospheric transmittance in the NIR as measured on the ground is enhanced substantially by multiple scattering of photons between the "bright" surface (in NIR region) and the cloud base. As a result, use of local surface albedo measured on the ground would systematically underestimate cloud absorption, which is a likely cause for the significant CAA in NIR as reported by O'Hirok et al. (2000) using ARESE I data. 
Using an areal-mean albedo, near perfect agreement is reached for both broadband (Fig.3) and spectral comparisons ( $\mathrm{Li}$ et al. 2002). Ackerman and Stokes (2003 thus declared that the CAA is now largely behind us. In parallel to the controversial findings related to the ARESE experiments, a number of other studies using data from different sources reach essentially the same conclusion (e.g. Francis et al. 1997; Chou et al. 1998).

\section{Concluding Remarks}

This paper reviews the state-of-the-art in solar radiation budget studies. Thanks to satellite observations, we have a rather accurate knowledge of the earth radiation budget at the top of the atmosphere. Prior to the EOS era, the monthly mean ERB at the GCM grid level was known to within $5 \mathrm{Wm}^{-2}$, but much larger errors existed for instantaneous and daily mean quantities. These errors are lowered by the new generation of ERB sensor (CERES) aboard the EOS. The disposition of the ERB between the atmosphere and the surface has also improved considerably through development of advanced satellite inversion algorithms and backed by an increasing number of high-quality ground-based observations. In general, the accuracy of the satellite-retrieved surface radiation budget is in par with that of the ERB, but much larger errors may occur in regions abundant of absorbing aerosols.

On the other hand, the disposition of solar energy between the surface and atmosphere simulated by GCMs usually suffers from larger errors of varying degrees. In the 1990s, the discovery of a systematic overestimation of the surface radiation budget by GCMs ignited long and fervent debates concerning cloud absorption anomaly (CAA). This paper presents a critical review of the debate in three phases: the initial phase of the mid-1990s, ARESE I phase and ARESE II phase. During the initial phase, different observational data sets and analysis methods were employed. While different observations drew controversial conclusions, the debate was centered on analysis methods and data employed. A major argument is if a proxy can denote cloud absorption, namely, the slope between TOA reflection and surface transmittance. It is shown that the ubiquitous presence of the horizontal exchange of solar photons always leads to a larger slope from models than from observations. In the ARESE I phase, the quality of the measurements used in studying the CAA came under scrutiny. Key measurements used to support the finding of a large CAA were found to be in serious error. A consensus on the CAA was finally reached during ARESE II, namely that there exists no CAA within the context of observation and modeling uncertainties.

The non-existence of the CAA in the magnitude as claimed before does not mean GCMs are free from systematic errors in simulating the solar radiation budget. Many GCMs are subject to numerous errors affecting the ERB, most notably, use of outdated radiative transfer codes and spectroscopic data base from which parameterization schemes are derived, a lack of or inadequate treatments of aerosol absorption, surface albedo, water vapor, etc. Presumbly inspired by the CAA debate, GCMs as a whole now have stronger absorption than before that are more consistent with observations. However, the enhancement stems from various factors but clouds (Barker and Li 1995, Francis et al. 1997, among others). 
Acknowledgement. The study is supported by the US Department of Energy's Atmospheric Radiation Measurement grant \#DE-FG02-01ER63166, and partly by the National Science Foundation of China (40028503). The author is grateful to the co-authors of his papers quoted here, in particular, Dr. A. Trishchenko, H.W. Barker, L. Moreau, and M. C. Cribb.

\section{References:}

Ackerman, S.A. and S.K. Cox, 1981: Aircraft observation of the shortwave fractional absorptance of non-homogeneous clouds, J. Appl. Meteor., 20, 1510-1515,

Ackerman, A.S., and O.B. Toon, 1996: Unrealistic desiccation of marine stratocumulus clouds by enhanced cloud absorption, Nature, 380, 512-517.

Ackerman, T.P., and G.M. Stokes, 2003, The Atmospheric Radiation Measurement program, Physics Today, January, 38-44.

Arking, Albert. 1999: Bringing climate models into agreement with observations of atmospheric absorption. J. Clim. 12, 1589-1600.

Arking, A., M.-D. Chou, and W.L. Ridgway, 1996: On estimating the effects of clouds on atmospheric absorption based on flux observations above and below cloud level, Geophy. Res. Let, 23, 829-832.

Arking, A., 1991: The radiative effects of clouds and their impact on climate, Bull Amer. Meteor. Soc., 72, 795-813.

Arking, A., and S. Vemury, 1984: The Nimbus 7 ERB data set: A critical analysis, J. Geophys. Res., 89, 5089-5097.

Arking, A., and J. S. Levine, 1967: Earth albedo measurements: July 1963 to June 1964, J. Atmos. Sci., 24, 721-724.

Abbot, C.G., and F.E. Fowle, 1908: in Annals of the Astrophysical Observatory of the Smithsonian Institution, Vol. 2, Smithsonian Institution, Washington, D.C.

Barker, H., Z. Li, and J.-P. Blanchet, 1994: Radiative characteristics of the Canadian Climate Centre second-generation general circulation model, J. Climate. 7: 1070-1091.

Barker, H.W., and Z. Li, 1995: Improved simulation of clear-sky shortwave radiative transfer in the CCC GCM, J. Climate, 8: 2213-2223.

Barker, H.W., and Z Li. 1997: Interpreting shortwave albedo-transmittance plots: True or apparent anomalous absorption. Geophy. Res. Let. 24, 2023-2026.

Barker, H.W., J.-J. Morcrette, and G.D. Alexander, 1998: Broadband solar fluxes and heating rates for atmospheres with 3 clouds, Q. J. R. Meteor. Soc., 124, 1245-1271.

Barkstrom, B., E. Harrison, G. Smith, R. Green, J. Kibler, R.D. Cess, and the ERB Science Team, 1989: Earth radiation budget experiment (ERBE) archival and April 1985 results, Bull. Amer. Meteor. Soc., 70, 1254-1262.

Budyko, M.I., 1956: Heat balance of the Earth's surface, 1958 translated in English, U.S. Weather Bureau, Dept. Commerce, Washington, D.C.

Budyko, M.I., 1982: The Earth's Climate: Past and Future, Academic Press, 307 pp.

Byrne, RN, RC J Somerville, and B Subasilar. 1996: Broken-cloud enhancement of solar radiation absorption." J. Atmos. Sci. 53,878 - 886.

Cess.R.D., G.L. Potter, and co-authors, 1989: Interpretation of cloud-climate feedbacks as produced by 14 atmospheric general circulation models, Science, 245, 513-516.

Cess. R.D., M.H. Zhang, and co-authors, 1995: Absorption of solar radiation by clouds: Observations versus models. Science, 267, 496-499. 
Cess, RD, MH Zhang, and co-Authors, 1996: Cloud feedback in atmospheric general circulation models: An update. J. Geophys. Res. 101,12791-12794.

Cess, R, F Valero, and co-authors. 1997. Absorption of solar radiation by the cloudy atmosphere: Interpretations of collocated aircraft measurements. J. Geophys. Res. 102, 29,917-29,927.

Chang, F-L, Z Li, and A Trishchenko, 2000: The dependence of TOA anisotropic reflection on cloud properties inferred from ScaRaB satellite data. J. Appl. Meteor. 39, 2480-2493.

Chou, M.-D., A. Arking, J. Otterman, W.L. Ridgway, 1995: The effect of clouds on atmospheric absorption of solar radiation, Geophy. Res. Letters, 22, 1885-1888.

Chou, M.-D., 1989: On the estimation of surface radiation using satellite data. Theor.Appl. Climat., 40,2536.

Chou, M.-D., W. Zhao, S.-H. Chou, 1998: Radiation budgets and cloud radiative forcing in the Pacific warm pool during TOGA COARE, J. Geophy. Res., 103, 16,967-16,977.

Davies, R., W.L. Ridgway, and K.E. Kim, 1984: Spectral absorption of solar radiation in cloudy atmosphere: A 20- $\mathrm{cm}^{-1}$ model. J. Atmos. Sci., 4, 2126-2137.

Dutton, E.G., J.J. Michalsky, and co-authors. 2001: Measurement of broadband diffuse solar irradiance using current commercial instrumentation with a correction for thermal offset errors. $J$. Atmos. and Ocean. Tech. 18, 297-314.

Foot, J.S., 1988: Some observations of the optical properties of clouds. Part I: Stratocumulus. Quart. J. Roy. Meteor. Soc., 114, 129-144.

Francis, P.N., J.P. Taylor, P. Hignett, and A. Slingo, 1997: On the question of enhanced absorption of solar radiation by clouds, Q. J. Meteor. Soc., 123, 419-434.

Fritz, S., 1951: Solar radiant energy, Compendium of Meteorology, T.F. Malone, Ed. Wiley and Sons, 1429.

Fritz, S., P. Rao and M. Weinstein, 1964: Satellite measurements of reflected solar energy and energy received at the ground. J. Atmos. Sci., 21,141-151.

Gauthier, C., G. Diak and S. Masse, 1980: A simple physical model to estimate incident solar radiation at the surface from GOES satellite data. J. Appl. Meteor., 19,1005-1012.

Hartmann, D.L., V. Ramanathan, A. Berroir, and G.E. Hunt, 1986: Earth radiation budget data and climate research, Rev. Geophy., 24, 439-468.

Hanson, K.J., T.H. Vonder Haar, and V.E. Suomi, 1967: Reflection of sunlight to space and absorption by the earth and atmosphere over the United States during spring 1962. J. Atmos. Sci., 95, 354-362.

Herman, G.F., and J.A. Curry, 1984: Observational and theoretical studies of solar radiation in Arctic stratus clouds, J. Climate Appl. Meteor., 23, 5-24.

Hignett, P., 1987: A study of the short-wave radiative properties of marine stratus: Aircraft measurements and model comparisons, Quart. J. Roy. Meteor. Soc., 113, 1011-1024.

House, F.B., A. Gruber, G.E. Hunt, and A.T. Mecherikunnel, 1986: History of satellite missions and measurements of the earth radiation budget (1957-1984), Rev. Geophy., 24, 357-377

Houghton, H.G., 1954: On the annual heat balance of the northern hemisphere, J. Meteor., 11, 1-9.

Hunt, G.E., R. Kandel, and A.T. Mecherikunnel, 1986: A history of pre-satellite investigations of the earth's radiation budget, Rev. Geophy., 24, 351-356.

Imre, D.G., E.H. Abramson, and P.H. Daum, 1996: Quantifying cloud-induced shortwave absorption: An examination of uncertainties and of recent arguments for large excess absorption, J. Appl. Meteor., 35, 1991-2010.

Jacobowitz, H., H.V. Soule, H.L. Kyle, F.B. House, and the NIMBUS 7 ERB Experiment Team, 1984: The Earth Radiation Budget (ERB) Experiment: An overview, J. Geophy. Res., 89, 5021-5038. 
Kiehl, JT, JJ Hack, and BP Briegleb. 1994. The simulated earth radiation budget of the National Center for Atmospheric Research Community Climate Model CCM2 and Comparisons with the Earth Radiation Budget Experiment (ERBE). J. Geophys. Res. 99, 20,815-20,827.

Kiehl, J.T., J.J. Hack, M.H. Zhang, and R.D. Cess, 1995: Sensitivity of a GCM climate to enhanced shortwave cloud absorption, J. Climate, 8, 2200-2212.

King, M.D., L.F. Radke, and P.V. Hobbs, 1990: Determination of the spectral absorption of solar radiation by marine stratocumulus clouds from airborne measurements within clouds, J. Atmos. Sci., 47, 894907.

Lacis, A.A., and J.E. Hansen, 1974, A parameterization for the absorption of solar radiation in the Earth's atmosphere, J. Atmos. Sci., 31, 118-132, 1974.

Li, Z., and H.G. Leighton, 1992: Narrowband to broadband conversion with spatially autocorrelated reflectance measurements, J. Appl. Meteor., 31, 421-432.

Li, Z., H.G. Leighton, 1993: Global climatologies of solar radiation budgets at the surface and in the atmosphere from 5 years of ERBE data, J. Geophy. Res., 98, 4919-4930.

Li, Z., H.G. Leighton, K. Masuda, and T. Takashima, 1993: Estimation of SW flux absorbed at the surface from TOA reflected flux, J. Climate, 6, 317-330.

Li, Z., and L. Garand, 1994: Estimation of surface albedo from space: A parameterization for global application, J. Geophy. Res., 99, 8335-8350.

Li, Z., 1995: Intercomparison between two satellite-based products of net surface shortwave radiation, J. Geophy. Res., 100, 3221-3232.

Li, Z, T. Charlock, and C. Whitlock, 1995: Assessment of the global monthly mean surface insolation estimated from satellite measurements using global energy balance archive data, J. Climate, 8 , 315-328.

Li, Z., H. Barker, and L. Moreau, 1995: The variable effect of clouds on atmospheric absorption of solar radiation, Nature, 376, 486-490.

Li, Z., and L. Moreau, 1996: Alteration of atmospheric solar absorption by clouds: Simulation and observation, J. Appl. Meteor., 35, 653-670.

Li, Z., 1996: On the angular correction of satellite-based radiation data: An evaluation of the performance of ERBE ADM in the Arctic, J. Theor. Appl. Climat. 54, 235-248.

Li, Z., L. Moreau, A. Arking, 1997: On solar energy disposition: a perspective from observation and modeling, Bull. Amer. Meteor. Soc., 78, 53-70

$\mathrm{Li}, \mathrm{Z}$., 1998, Influence of absorbing aerosols on the inference of solar surface radiation budget and cloud absorption, J. Climate, 11, 5-17.

Li, Z., and L. Kou, 1998, Atmospheric direct radiative forcing by smoke aerosols determined from satellite and surface measurements, Tellus (B), 50, 543-554.

Li, Z., A. Trishchenko, H.W. Barker, G.L. Stephens, P.T. Partain, 1999: Analysis of Atmospheric Radiation Measurement (ARM) programs's Enhanced Shortwave Experiment (ARESE) multiple data sets for studying cloud absorption, J. Geophy. Res. 104, 19127-19134.

Li, Z., and A. Trishchenko, 1999, A study towards an improved understanding of the relationship between visible and SW albedo measurements, J. Atmos. \& Ocean. Tech. 16, 347-360.

Li, Z., A. Trishchenko, 2001, Quantifying the uncertainties in determining SW cloud radiative forcing and cloud absorption due to variability in atmospheric condition, J. Atmos. Sci., 58, 376-389.

Li, Z., M. Cribb, A. Trishchenko, 2002, Impact of surface inhomogeneity on solar radiative transfer under overcast conditions, J. Geophy. Res., 107, 10.1029/2001JD000976. 
Loeb, N.G., N.M. Smith, and co-authors, 2002: Angular distribution models for top-of-atmosphere radiative flux estimation from the clouds and the earth's radiant energy system instrument on the tropical rainfall measuring mission satellite, Part I, methodology, J. Appl. Meteor., in press.

London, J., 1957: A study of the atmospheric heat balance, Final Report, AFC-TR-57-287, OTSPB129551, 99pp., New York Univ., New York.

Masuda, K., H.G. Leighton, and Z. Li, 1995: A new parameterization for the determination of solar flux absorbed at the surface from satellite measurements, J. Climate., 8, 1615-1629.

Marshak, A, A Davis, W Wiscombe, and R Cahalan. 1997: Inhomogeneity effects on cloud shortwave absorption: Two-aircraft simulations. J. Geophys. Res. 102, 619-16637.

Marshak, A, A Davis, W Wiscombe, W Ridgway, and R Cahalan. 1998: Biases in shortwave column absorption in the presence of fractal clouds. J. Climate, 11, 431-446.

Marshak, A, W.J. Wiscombe, A.B. Davis, L. Oreopoulos, and R.F. Cahalan. 1999: On the removal of the effect of horizontal fluxes in two-aircraft measurements of cloud absorption. Quart. J. Roy. Meteor. Soc. 125, 2153-2170.

Michalsky, J, E Dutton, and co-authors. 1999: Optimal measurement of surface shortwave irradiance using current instrumentation. J. Atmos. \& Oceanic Tech. 16: 55-69.

Michalsky, J., et al., 2001: Broadband and spectral shortwave calibration results from ARESE II, paper presented at 11th Annual ARM Science Team Meeting, Dep. of Energy, Atlanta, Georgia, March 19-23, 2001. [Available on-line: www.arm.gov].

Minnis, P., and E.F. Harrison, 1984: Diurnal variability of regional cloud and clear-sky radiative parameters derived from GOES data, III: November 1979 radiative parameters, J. Climate and Appl. Meteor., 23, 1032-1050.

Minnis, P., W. L. Smith Jr. 1998: Cloud and radiative fields derived from GOES-8 during SUCCESS and the ARM-UAV Spring 1996 Flight Series, Geophys. Res. Lett., 25, 1113-1116.

Minnis, P. L. Nguyen, D. Doelling, D. Young, W. Miller, D. Kratz, 2002: Rapid calibration of operational and research meteorological satellite imagers. Part I: Evaluation of research satellite visible channels as references. J. Atmos. \& Ocean. Tech., 19, 1233-1249.

Möser, W., and E. Raschke, 1983: Mapping of global radiation and of cloudiness from METEOSAT image data. Meteor Rundsch., 36, 33-41.

O'Hirok, W, and C Gautier. 1998. A three-dimensional radiative transfer model to investigate the solar radiation within a cloudy atmosphere Part II: Spectral effects. J. Atmos. Sci. 55, 3065-3076.

O'Hirok, W., C. Gautier, and P. Ricchiazzi. 2000: Spectral signature of column solar radiation absorption during the Atmospheric Radiation Measurement Enhanced Shortwave Experiment (ARESE), J. Geophys. Res. 105, 17,471 - 17,480.

Ohmura, A., and H. Gilgen, 1991: Global Energy Balance Archive (GEBA), World Climate Program Water Project A7, Rep.2: The GEBA Database, Interactive Application, Retrieving Data. Zurich, Verlag der Fachvereine, $60 \mathrm{pp}$.

Ohmura, A., and H. Gilgen, 1993: Re-evaluation of the global energy balance. Geophy. Monogra. 75. , IUGG Vol. 15, 93-110, 1993.

Pilewskie, P., and F. Valero, 1995: Direct observations of excess solar absorption by clouds. Science, 257, 1626-1629.

Pinker, R.T., R. Frouin, and Z. Li, 1995: A review of satellite methods to derive surface shortwave irradiance, Remote Sens. Environ., 51, 108-124.

Pinker, R.T., and I. Laszlo, 1992: Modelling surface solar irradiance for satellite applications on a global scale. J. Appl. Meteor., 31, 194-211 
Pinker, R.T., and J.A. Ewing, 1985: Modelling surface solar radiation: model formulation and validation. $J$. Climate Appl. Meteor., 24,389-401.

Randall, DA, RD Cess, and co-Authors, 1992: Intercomparison and interpretation of surface energy fluxes in atmospheric general circulation models. J. Geophys. Res. 97, 3711-3724.

Ramanathan, V., B. Subasilar, and co-authors, 1995: Warm pool heat budget and shortwave cloud forcing: A missing physics, Science, 267, 499-503.

Ramanathan, V ,1987: The role of earth radiation budget studies in climate and general circulation research, J. Geophy. Res., 92, 4075-4095.

Randall, D.A, R.D. Cess, and co-authors, 1992: Intercomparison and interpretation of surface energy fluxes in atmospheric general circulation models, J. Geophy. Res., 97, 3711-3724.

Raschke, E., T.H. Vonder Haar, W.R. Bandeen, and M. Pasternak, 1973: The annual radiation balance of the earth-atmosphere system during 1969-70 from Nimbus 3 measurements, J. Atmos. Sci., 30, 341-364.

Rawlins, F., 1989: Aircraft measurements of the solar absorption by broken cloud fields: A case study, Quart. J. Roy. Meteor. Soc., 115, 365-382.

Robinson, 1958, G.D., 1958: Some observations from aircraft of surface albedo and the albedo and absorption of cloud, Arch. Meteor. Geophy. Bioklimatol., B9, 28-41.

Reynolds D.W., T.H. Vonder Harr, and S.K. Cox, 1975: The effect of solar radiation absorption in the tropical atmosphere, J. Appl. Meteor., 14, 433-444.

Rossow, W.B., and Y.-C. Zhang, 1995: Calculation of surface and top of atmosphere radiative fluxes from physical quantities based on ISCCP data sets, 2. Validation and first results, J. Geophys. Res., 97, 1167-1197.

Rossow, W.B., and R.A. Schiffer, 1991: ISCCP cloud data products, Bull. Am. Meteor. Soc., 72, 2-20.

Sasamori, T., J. London, and D.V. Hoyt, 1972: Radiation budget of the southern hemisphere, Meteor. Monogr., 13.

Schmetz, J., 1989: Towards a surface radiation climatology: Retrieval of downward irradiance from satellite, Atmos. Res., 23, 287-321.

Simpson, G.C., 1929: The distribution of terrestrial radiation, Mem. R. Meteor. Soc., 3, 36-41.

Slingo, A., S. Nicholls, and J. Schmetz, 1982: Aircraft observations of marine stratocumulus during JASIN. Quart. J. Roy. Meteor. Soc., 108, 833-856.

Stephens, G.L., G.G. Campbell, and T.H. Vonder Haar, 1981: Earth radiation budgets, J. Geophy. Res., 86, 9739-9760.

Stephens, G.L., and S.-C. Tsay, 1990: On the cloud absorption anomaly, Quart. J. Roy. Meteor. Soc., 116, 671-704.

Stephens, G.L., and T.J. Greenwald, 1991: The earth's radiation budget and its relation to atmospheric hydrology. 2. Observations of cloud effects, J. Geophy. Res., 96, 15,325-15340.

Stephens, G.L., 1996: How much solar radiation do clouds absorb?, Science, 271, 1131-1133.

Stephens, G.L., R.F. McCoy Jr, R.B. McCoy, P.G., P.T. Partain, and S.D. Miller. 2000. A multipurpose Scanning Spectral Polarimeter (SSP): Instrument description and sample results. $J$. Atmos. \& Oceanic Tech., 17, 616-627.

Stuhlmann, R., M. Rieland and E. Raschke, 1990: An improvement of the IGMK model to derive total and diffuse solar radiation at the surface from satellite data. J. Appl. Meteor., 29,586-603.

Stuhlmann, R., and E. Raschke, 1987: Satellite measurements of the earth radiation budget: sampling and retrieval of shortwave exitances - a sampling study, Beitr. Phys. Atmos., 60, 393-410. 
Suttles, J.T., Green, R.N., Minnis, P., and co-authors, 1988: Angular radiation models for Earthatmosphere system. Vol. 1- shortwave radiation. NASA Refer. Publ., 1184, 114 pp.

Suttles, J.T., B.A. Wielicki, and S. Vemury, 1992: Top-of-atmosphere radiation fluxes: validation of ERBE scanner inversion algorithm using NIMBUS-7 ERB data, J. Appl. Meteor., 31, 784-796.

Suttles, J.T., and G. Ohring, 1986: Surface radiation budget for climate applications. NASA Reference Publication 1169, $132 \mathrm{pp}$.

Tarpley, J.D., 1979: Estimating incident solar radiation at the surface from geostationary satellite data. $J$. Appl. Meteor., 18,1172-1181.

Taylor, V.R., and L.L. Stowe, 1984: Reflectance characteristics of uniform earth and cloud surfaces derived from Nimbus-7 ERB, J. Geophy. Res., 89, 4987-4996.

Trishchenko, Alexander, and Zhanqing Li. 1998: Use of ScaRaB measurements for validating a GOES-based TOA radiation product. J. Appl. Meteor. 37: 591-605.

Valero, FPJ, RD Cess, and co-authors, 1997: Absorption of Solar Radiation by Clouds: Interpretations of Collocated Aircraft Measurement. J. Geophys. Res. 104, 29,917-29,927.

Valero, FP J, P Minnis, and co-authors 2000: The absorption of solar radiation by the atmosphere as determined using consistent satellite, aircraft, and surface data during the ARM Enhanced ShortWave Experiment (ARESE). J. Geophys. Res. 105, 4743-4758.

Vonder Haar, T.H., and V.E. Suomi, 1971: Measurements of the earth's radiation budget from satellites during a five-year period. Part I: extended time and space means, J. Atmos. Sci., 28, 305-314.

Ward, D.M., 1995: Comparison of the surface solar radiation budget derived from satellite data with that simulated by the NCAR GCM2, J. Climate, 8, 2824-2842.

Wielicki, B.A., R.D. Cess, M.D. King, D.A. Randall, and E.F. Harrison, 1995: Mission to planet Earth: Role of clouds and radiation in climate, Bull. Amer. Meteor. Soc., 76, 2125-2153.

Wielicki, B.A., B.R. Barkstrom, and co-authors, 1996: Clouds and the Earth's Radiative Energy System (CERES): An earth observing system experiment. Bull. Amer. Meteor. Soc., 76, 2125-2153.

Wild, M., A. Ohmura, H. Gilgen, and E. Roeckner, 1995: Validation of general circulation model radiative fluxes using surface observations. J. Climate, 8, 1309-1324.

Wiscombe, W.J., R.M. Welch, and W.D. Hall, 1984: The effects of very large drops on cloud absorption, Part I: Parcel models. J. Atmos. Sci., 41, 1336-1355.

Wiscombe, W.J., 1995: Atmospheric physics: An absorption mystery. Nature, 376, 466-467.

Zender, C. S., B. Bush, and co-authors, 1997: Atmospheric absorption during the Atmospheric Radiation Measurement (ARM) Enhanced Shortwave Experiment (ARESE), J. Geophys. Res. 102, 29,901-29,916.

Zhang, M.H., W.Y. Lin, and J.T. Kiehl, 1998: Bias of atmospheric shortwave absorption in the NCAR CCM2 and CCM3: Comparison with monthly ERBE/GEBA measurements, J. Geophys. Res. 103, 8919-8925.

Zhang, Y., Z. Li, A. Macke, 2002, Retrieval of surface solar radiation budget under ice cloud sky: uncertainty analysis and parameterization, J. Atmos. Sci., 59, 2951-2965. 